\title{
Antimicrobial Resistance of Salmonella Serotypes Isolated from Slaughter-Age Pigs and Environmental Samples
}

\author{
CELSO JOSÉ BRUNO OLIVEIRA, ${ }^{1}$ LUIZ FERNANDO OLIVEIRA SILVA CARVALHO, ${ }^{2}$ \\ SUELI APARECIDA FERNANDES, ${ }^{3}$ ANA TEREZINHA TAVECHIO, ${ }^{3}$ \\ CLAUDIO CAMACHO PEREIRA MENEZES, ${ }^{2}$ and FRANCISCO JOSÉ DOMINGUES, JR. ${ }^{2}$
}

\begin{abstract}
The aim of this study was to determine the antimicrobial resistance patterns of Salmonella strains isolated from slaughter-age pigs and environmental samples collected at modern swine raising facilities in Brazil. Seventeen isolates of six serotypes of Salmonella enterica subsp. enterica were isolated out of 1,026 collected samples: Salmonella Typhimurium (1), Salmonella Agona (5), Salmonella Sandiego (5), Salmonella Rissen (1), Salmonella Senftenberg (4), and Salmonella Javiana (1). Resistance patterns were determined to extendedspectrum penicillin (ampicillin), broad-spectrum cephalosporins (cefotaxime and ceftriaxone), aminoglycosides (streptomycin, neomycin, gentamicin, amikacin, and tobramycin), narrow-spectrum quinolone (nalidixic acid), broad-spectrum quinolone (ciprofloxacin and norfloxacin), tetracycline, trimethoprim, and chloramphenicol. Antimicrobial resistance patterns varied among serotypes, but isolates from a single serotype consistently showed the same resistance profile. All isolates were resistant to tetracycline, streptomycin, and nalidixic acid. One isolate, Salmonella Rissen, was also resistant to cefotaxime and tobramycin. All serotypes were susceptible to ceftriaxone, norfloxacin, ciprofloxacin, ampicillin, gentamicin, and chloramphenicol. The high resistance to tetracycline and streptomycin may be linked to their common use as therapeutic drugs on the tested farms. No relation was seen between nalidixic acid and fluoroquinolone resistance.
\end{abstract}

\section{INTRODUCTION}

$\mathbf{N}$ ONTYPHOIDAL SALMONELLOSIS has become an important cause of enteric infections in many countries, ${ }^{17,23,30}$ and several human salmonellosis outbreaks linked to the consumption of contaminated pork have been reported during the last decade..$^{3,20,22,24,29}$ Furthermore, antibiotic-resistant strains have emerged worldwide and have led to increasing consumer concern about animal-derived food consumption. Infections caused by resistant strains have shown a higher fatality rate compared to those caused by susceptible organisms. ${ }^{15}$

The extensive use of antibiotics on farms for both therapeutic and growth promotion purposes have been considered to be an important trigger for the emergence of antibiotic-resistant pathogens, $, 14,33$ and their real impact on public health contin- ues to be a matter of debate. High numbers of tetracycline-resistant Salmonella strains have been isolated from pig farms. ${ }^{7,34}$ However, resistance to first-choice antibiotics used for treatment of human infections causes even more concern. An increasing number of reports on Salmonella isolates from animals and humans show reduced susceptibility to fluoroquinolones. ${ }^{2,31,35}$ Also, resistance to third-generation cephalosporins has been recently published.,5

Considering the marked importance of Salmonella organisms as food-borne pathogens and the world-wide emergence of resistant or multidrug-resistant Salmonella strains, ${ }^{6,33}$ in the present paper we describe the antimicrobial resistance patterns of Salmonella serotypes isolated from pigs and environmental samples collected from modern swine-raising systems in Brazil.

\footnotetext{
${ }^{1}$ Departamento de Patologia Animal, Faculdade de Ciências Agrárias e Veterinárias, Unesp campus de Jaboticabal, 14 884-900, Jaboticabal, SP, Brasil.

${ }^{2}$ Departamento de Clínica e Cirurgia Veterinária da Faculdade de Ciências Agrárias e Veterinárias, Unesp campus de Jaboticabal, Jaboticabal, SP, Brazil 14 884-900.

${ }^{3}$ Instituto Adolfo Lutz, setor de Bacteriologia, Bairro Cerqueira César, São Paulo-SP, Brazil 01246-902.
} 


\section{MATERIALS AND METHODS}

Antibiotic resistance patterns were studied in 17 Salmonella strains previously isolated from four pig farms located in São Paulo State, Brazil (Oliveira et al., manuscript submitted). Sixteen positive samples were isolated out of 1,026 collected samples and the serotypes of Salmonella enterica subsp. enterica comprised Salmonella Typhimurium (1), Salmonella Agona (5), Salmonella Sandiego (5), Salmonella Rissen (1), Salmonella Senftenberg (4), and Salmonella Javiana (1). Sixteen positive samples were identified out of all samples collected, including feces, feed, floors, feeders, and water. Two different serotypes ( $S$. Agona and $S$. Sandiego) were cultured from a single positive fecal sample. Bacteriological procedures for feces and water samples were followed as previously described.,12 Floor and feeder samplings were performed after the animals were removed and the pens disinfected, using drag swab sets. ${ }^{21}$ The isolated Salmonella strains were serotyped according to Popoff and Le Minor. ${ }^{27}$ Resistance to each antibiotic was determined by the Kirby-Bauer disk susceptibility test ${ }^{28}$ using commercially prepared filter paper disks (Oxoid Ltd., Hampshire, UK), each impregnated with a specified amount of an antibiotic. The antibiotics tested and respective breakpoints were as follows: extended spectrum penicillin (ampicillin, $\geq 32 \mu \mathrm{g} / \mathrm{ml}$ ); broad-spectrum cephalosporins (cefotaxime, $\geq 64 \mu \mathrm{g} / \mathrm{ml}$; ceftriaxone, $\geq 64 \mu \mathrm{g} / \mathrm{ml}$ ); aminoglycosides (streptomycin, $\geq 2,000 \mu \mathrm{g} / \mathrm{ml}$; neomycin, $\geq 16 \mu \mathrm{g} / \mathrm{ml}$; gentamicin, $\geq 16 \mu \mathrm{g} / \mathrm{ml}$; amikacin, $\geq 64 \mu \mathrm{g} / \mathrm{ml}$; tobramycin, $\geq 16 \mu \mathrm{g} / \mathrm{ml})$; narrow-spectrumquinolone (nalidixic acid, $\geq 32 \mu \mathrm{g} / \mathrm{ml}$ ); broadspectrum quinolones (ciprofloxacin, $\geq 4 \mu \mathrm{g} / \mathrm{ml}$; norfloxacin, $\geq 16 \mu \mathrm{g} / \mathrm{ml}$; tetracycline, $\geq 16 \mu \mathrm{g} / \mathrm{ml}$; trimethoprim, $\geq 16 \mu \mathrm{g} / \mathrm{ml}$; chloramphenicol, $\geq 32 \mu \mathrm{g} / \mathrm{ml}$ ). The results were analyzed and interpreted according to the guidelines of the $\mathrm{Na}$ tional Committee for Clinical Laboratory Standards (NCCLS). ${ }^{25}$ Briefly, after pre-inoculation in tryptone soy broth and adjustment of turbidity to a $0.5 \mathrm{McFarland}$ turbidity standard, bacterial suspensions were streaked onto freshly prepared Mueller-Hinton agar plates (Oxoid Ltd., Hampshire, UK) using sterile swabs. The reference strains used were Escherichia coli ATCC 25922 and Pseudomonas aeruginosa ATCC 27853. Seven disks were placed on each 150-mm plate after 5 min to allow any excess surface moisture to be absorbed, and plates were aerobically incubated for $16-18 \mathrm{hr}$ at $35^{\circ} \mathrm{C}$. The strains were finally interpreted as resistant, intermediate or susceptible to each antibiotic according to the criteria currently recommended by the NCCLS, based on the diameters of the zones of complete inhibition to the nearest whole millimeter.

\section{RESULTS}

Seventeen Salmonella strains were isolated out of 1,026 samples collected. The Salmonella serotypes identified and the types of samples from which they were detected are shown in Table 1. The antimicrobial resistance patterns are shown in Table 2. Susceptibility varied among serotypes, but isolates from a single serotype showed the same resistance pattern. All isolates were resistant to at least three antimicrobial agents, tetracycline, streptomycin, and nalidixic acid. One isolate, $\mathrm{Sal}$ monella Rissen, was also resistant to cefotaxime and tobramycin. All serotypes were susceptible to ceftriaxone, norfloxacin, ciprofloxacin, ampicillin, gentamicin, and chloramphenicol. Fifteen isolates showed intermediate resistance to neomycin. Intermediate resistance to amikacin (3), trimethoprim (3), nalidixic acid (1), tobramycin (1), and cefotaxime (1) was detected as well. The serotypes from farm A were isolated from different types of samples; however, a very similar antimicrobial resistance profile was seen for these strains (Table 2).

\section{DISCUSSION}

Considering the marked importance of Salmonella enterica serotypes as food-borne pathogens ${ }^{19}$ and the world-wide emergence of resistant or multidrug-resistant Salmonella strains, ${ }^{16,33}$ our goal was to report the antibiotic resistance profiles of Salmonella strains isolated from pigs and environmental samples collected from modern swine raising systems in Brazil. Despite the marked limitation of this study due to the small number of isolates (16 out of 1,026 samples), some results may be discussed.

All Salmonella isolates collected from four pig farms showed resistance to tetracycline and streptomycin. Although these antibiotics are not allowed for use as growth promoters by Brazilian legislation, they have been used by veterinarians for clini-

Table 1. Number of Salmonella Serotypes Cultured from Swine Farms A, B, C, and D, Located in São Paulo State (Brazil), Considering the Types of Samples from Which They Were Isolated

\begin{tabular}{lll}
\hline Test farm & \multicolumn{1}{c}{ Serotype (number of isolates) } & \multicolumn{1}{c}{ Samples (number of positive samples) } \\
\hline & Salmonella Agona (3) & Rectal feces (1), dunging gutter water (2) \\
& Salmonella Agona (1) & Rectal feces (1) \\
A & Salmonella Sandiego (4) & Pool of feces (2), feed (1) drinking water (1) \\
& Salmonella Javiana (1) & Rectal feces (1) \\
B & Salmonella Agona (1) + Salmonella Sandiego (1) ${ }^{\mathrm{a}}$ & Rectal feces (1) \\
C & Salmonella Rissen (1) & Rectal feces \\
& Salmonella Senftenberg (2) & Rectal feces (2) \\
D & Salmonella Senftenberg (2) & Rectal feces (2), pool of feces (2) \\
\hline
\end{tabular}

asolation of two serotypes from one fecal sample. 
Table 2. Antimicrobial Resistance Patterns from 17 Salmonella Strains Isolated from Different Types of Samples Collected on Intensive Pig Farms Located in São Paulo, Brazil

\begin{tabular}{|c|c|c|c|}
\hline Sample & $\begin{array}{c}\text { Serotype } \\
\text { (number of isolates) }\end{array}$ & Total resistance pattern & $\begin{array}{c}\text { Intermediate } \\
\text { resistance pattern }\end{array}$ \\
\hline \multirow[t]{5}{*}{ Rectal feces } & Salmonella Agona (3) & $\mathrm{Str} / \mathrm{Tet} / \mathrm{Nal}$ & $\mathrm{Tm} / \mathrm{Neo}$ \\
\hline & Salmonella Rissen (1) & Ctx/Str/Tet/Tob & $\mathrm{Tm} / \mathrm{Nal} / \mathrm{Neo}$ \\
\hline & Salmonella Senftenberg (2) & Str/Tet/Nal & Ami/Neo/Tob \\
\hline & Salmonella Javiana (1) & Str/Tet/Nal & Neo \\
\hline & Salmonella Sandiego (1) & Str/Tet/Nal & Neo \\
\hline Feed & Salmonella Sandiego (1) & Str/Tet/Nal & Neo \\
\hline \multirow{2}{*}{ Pool of feces } & Salmonella Senftenberg (2) & Str/Tet/Nal & Ami/Neo/Tob \\
\hline & Salmonella Sandiego (2) & Str/Tet/Nal & $\mathrm{Neo}$ \\
\hline Drinking water & Salmonella Sandiego (1) & Str/Tet/Nal & Neo \\
\hline Clean feeder & Salmonella Typhimurium (1) & Str/Tet/Nal & $\mathrm{Ctx} / \mathrm{Ami}$ \\
\hline Dunging gutter water & Salmonella Agona (2) & Str/Tet/Nal & $\mathrm{Tm} / \mathrm{Neo}$ \\
\hline
\end{tabular}

The antimicrobial agents tested were: cefotaxime (Ctx), ceftriaxone (Cro), amikacin (Ami), norfloxacin (Nor), streptomycin (Str), trimethoprim (Tm), neomycin (Neo), tobramycin (Tob), ciprofloxacin (Cip), tetracycline (Tet), ampicillin (Amp), gentamicin (Gen), nalidixic acid (Nal), and chloramphenicol (Chl).

cal therapy on the tested farms. Furthermore, high frequencies of isolates resistant to tetracycline have been also detected in Salmonella isolates of swine origin collected in other countries. ${ }^{7,34}$ In the United States, $84.2 \%$ of Salmonella strains isolated from swine were found to be resistant to tetracycline? It is likely that a link might exist between the long-term therapeutic use of certain antibiotics and the high number of isolates showing resistance patterns to them. Furthermore, the use of antimicrobials has been implicated in the emergence and maintenance of resistant determinants in various ecosystems. ${ }^{9,22,26}$ However, the real impact of the therapeutic use of these antibiotics in farm animals on the spread of resistance remains to be clarified.

We detected Salmonella Rissen resistant to cefotaxime. Some recent reports ${ }^{4,5,8}$ also showed resistance of other Salmonella strains to third-generation cephalosporins. Despite the importance of expanded-spectrum cephalosporins in the treatment of invasive salmonellosis in children, the incidence of Salmonella resistant to them remains very low. No resistance to cefotaxime was detected in 1,257 Salmonella isolates from the United States. ${ }^{7}$ Furthermore, Salmonella Rissen has been rarely isolated from human sources in Brazil. In a retrospective study on Salmonella isolates from human sources in Brazil from 1991 to $1995,{ }^{17}$ only 4 Salmonella Rissen strains were isolated from human sources compared to 200 strains of Salmonella Typhimurium. For these reasons, we believe that the isolation of a cefotaxime-resistant Salmonella Rissen strain may not be a direct concern to human health but could be an important observation because such resistance could be transferred to other important pathogenic serotypes.

Treatments failed when fluoroquinolones were used to treat Salmonella infections caused by nalidixic acid-resistant strains. ${ }^{13,24}$ Indeed, Salmonella isolates resistant to nalidixic acid have been shown to be less susceptible to fluoroquinolones. ${ }^{35,36}$ Strains showing decreased susceptibility to ciprofloxacin, ofloxacin, and norfloxacin have been reported to be uniformly resistant to nalidixic acid, a fact attributed to a mutation in the gyrA gene..$^{10,11}$ Conversely, our results showed that all strains were nalidixic acid resistant but norfloxacin and ciprofloxacin susceptible, corroborating data previously reported in The Netherlands. ${ }^{18}$ Therefore, no link between nalidixic acid and fluoroquinolone resistance was detected. We believe this is an important point because fluoroquinolone resistance has received special attention from the scientific community. Many reports have indicated a possible link between the increased recovery of Salmonella organisms showing reduced susceptibility to ciprofloxacin and the importance of using quinolones in farm animals, with the consequent emergence of fluoroquinolones resistance. ${ }^{10,32}$

Curiously, all Salmonella serotypes from farm A showed a very similar resistance profile, despite the fact that the serotypes isolated may develop antibiotic resistance through different mechanisms. ${ }^{35}$ This result may indicate that horizontal gene transfer between bacteria is important to resistant genes spreading in a given environment, supporting previous reports. ${ }^{15} \mathrm{How}-$ ever, conclusions should be reached with caution because all serotypes were theoretically submitted to the same antimicrobial selective pressure on such farm. Further work looking at the genetic characterization of resistance determinants is underway to determine the identity and homology of resistance genes.

The isolation of a multiresistant Salmonella Typhimurium strain from a clean and supposedly disinfected feeder may indicate failures of biosecurity procedures that play an important role in the introduction and maintenance of resistant serotypes on farms. Nevertheless, further studies of the risk factors that might contribute to the maintenance of resistant Salmonella strains are needed.

There is a one-way trend worldwide to implement changes in pig production toward health-oriented systems. This is a crucial attitude for the reduction of antibiotic use on farms, since the benefits of such drugs are emphasized in systems with low hygienic standards. ' Several antibiotics earlier used as growth promoters have been banned in Brazil and at this time only 14 antibiotics are allowed for use on pig farms for this purpose. Furthermore, special attention has been paid to the therapeutic use of antibiotics for farm animals in this country.

Finally, we also assume that the implementation and im- 
provement of biosecurity procedures on pig farms have a great potential to prevent the maintenance of resistant strains through internal cycles of contamination. To test this hypothesis, further studies focusing on the dynamics of resistance transfer in the environment and among animals are needed.

\section{ACKNOWLEDGMENTS}

The authors are grateful to Dr. Wondwossen Gebreyes (North Carolina State University) for his advice during the preparation of the manuscript and to Fundação de Amparo à Pesquisa do Estado de São Paulo (FAPESP) and Conselho Nacional de Pesquisa (CNPq) for financial support.

\section{REFERENCES}

1. Davies, P.R., F.G.E.M. Bovee, J.A. Funk, W.E.M. Morrow, F.T. Jones, and J. Deen. 1998. Isolation of Salmonella serotypes from feces of pigs raised in a multiple site production system. J. Am. Vet. Med. Assoc. 212:1925-1929.

2. Davies, R.H., C.J. Teale, C. Wray, I.M. McLaren, Y.E. Jones, S. Chappell, and S. Kidd. 1999. Nalidixic acid resistance in salmonella isolated from turkeys and other livestock in Great Britain. Vet. Rec. 144:320-322.

3. Delpech, V., J. McAnulty, and K. Morgan. 1998. A salmonellosis outbreak linked to internally contaminated pork meat. Aust. NZ Public Health. 22:243-246.

4. Dunne, E.F., P.D. Fey, P. Kludt, R. Reporter, F. Motashari, P. Shillam, J. Wicklund, C. Miller, B. Holland, K. Stamey, T.J. Barrett, J.K. Rasheed, F.C. Tenover, E.F. Ribot, and F.J. Angulo. 2000. Emergency of domestically acquired ceftriaxone-resistant Salmonella infections associated with AmpC B-lactamase. J. Am. Med. Assoc. 284:3151-3156.

5. Fey, P.D., T.J. Safranek, and M.E. Rupp. 2000. Ceftriaxone-resistant Salmonella infection acquired by a child from cattle. N. Engl. J. Med. 342:1242-1249.

6. Flensburg, J. 1999. Programmes to control or eradicate salmonella in animal production in Denmark. Acta Vet. Scand. Suppl. 91:51-58.

7. Gebreyes, W.A., P.R. Davies, W.E.M. Morrow, J.A. Funk, and C. Altier. 2000. Antimicrobial resistance of Salmonella isolates from swine. J. Clin. Microbiol. 38:4633-4636.

8. Gray, J.T., P.J. Fedorka-Cray, J. Hermosillo, and M. Headrick. 2001. Expanded-spectrum cephalosporin resistance and multi-drug resistance in Salmonella isolates from swine. In: International Symposium on the epidemiology and control of salmonella and other food borne pathogens in pork, 4th Proceedings. Leipzig, 2001, p. 377.

9. Greko, C. 1999. Antibiotics as growth promoters. Acta Vet. Scand. Suppl. 92:87-100.

10. Griggs, D.J., K. Gensberg, and L.J.V. Piddock. 1996. Mutations in gyrA gene of quinolone-resistant Salmonella serovars isolated from humans and animals. Antimicrob. Agents Chemother. 40:1009-1013.

11. Hakanen, A., P. Kotilainen, J. Jalava, A. Siitonen, and P. Huovinen. 1999. Detection of decreased fluoroquinolone susceptibility in salmonellas and validation of nalidixic acid screening test. J. Clin. Microbiol. 37:3572-3577.

12. Henry, D.P., A.J. Forst, D. O'Boyle, and R.D. Cameron. 1995. The isolation of Salmonellas from piggery waste water after orthodox pondage treatment. Aust. Vet. J. 72:478-479.

13. Hof, H., I. Ehrhard, and H. Tschäpe. 1991. Presence of quinolone resistance in a strain of Salmonella typhimurium. Eur. J. Clin. Microbiol. Infect. Dis. 10:747-749.

14. Holmberg, S.D., M.T. Osterholm, K.A. Senger, and M.L. Cohen. 1984. Drug-resistant salmonella from animals fed antimicrobials. N. Engl. J. Med. 311:617-622.

15. Holmberg, S.D., J.G. Wells, and M.L. Cohen. 1984. Animalto-man transmission of antimicrobial-resistant salmonella: Investigation of U.S. outbreaks, 1971-1983. Science 225:833835.

16. Huovinen, P. 1999. Bacterial resistance; an emergence health problem. Acta Vet. Scand. Suppl. 92:7-13.

17. Irino K., S.A. Fernandes, A.T. Tavechio, B.C. Neves, and A.M.G. Dias. 1996. Progression of Salmonella Enteritidis phage type 4 strains in São Paulo State, Brazil. Rev. Inst. Med. Trop. S. Paulo. 38:193-196.

18. Jacods-Reitsma, W.F., P.M.F.J. Koenraad, N.M. Bolder, and R.W.A.W. Mulder. 1994. In vitro susceptibility of Campylobacter and Salmonella isolates from broilers to quinolones, ampicillin, tetracycline, and erythromycin. Vet. Qu. 16:206-208.

19. Kruse, H. 1999. Globalization of the food supply-food safety implications. Special regional requirements: future concerns. Food Control 10:315-320.

20. Llewellyn, L.J., M.R. Evans, and S.R. Palmer. 1998. Use of sequential case control studies to investigate a community Salmonella outbreak in Wales. J. Epidemiol. Commun. Health 52:272-276.

21. Mallinson E.T., C.R. Tate, R.G. Miller, B. Bennett, and E. Russek-Cohen. 1989. Monitoring poultry farms for Salmonella by drag-swab sampling and antigen-capture immunoassay. Avian Dis. 33:684-690.

22. Maguire, H.C., A.A. Codd, V.E. Mackay, B. Rowe, and E. Mitchell. 1993. A large outbreak of human salmonellosis traced to a local pig farm. Epidemiol. Infect. 10:239-246.

23. Metzer, E., V. Agmon, N. Andoren, and D. Cohen. 1998. Emergence of multidrug-resistant Salmonella enterica serotype Typhimurium phage-type DT 104 among salmonellae causing enteritis in Israel. Epidemiol. Infect. 121:555-559.

24. Molbak, K., D.L. Baggesen, F.M. Aarestrup, J.M. Ebbesen, J. Engberg, K. Frydendahl, P. Gerner-Smidt, A.M. Petersen, and H.C. Wegener. 1999. An outbreak of multiresistant, quinolone-resistant Salmonella enterica serotype TyphimuriumDT104. N. Engl. J. Med. 341:1420-1425.

25. National Committee for Clinical Laboratory Standards. 1998. Performance standards for antimicrobial susceptibility disk and dilution susceptibility tests for bacteria isolated from animals, approved standard M31-A. National Committee for Clinical Laboratory Standards, Wayne, PA.

26. Olsen, J.E. 1999. Antibiotic resistance: genetic mechanisms and mobility. Acta Vet. Scand. Suppl. 92:15-22.

27. Popoff, M.Y., and L. Le Minor. 1997. Antigenic formulas of the Salmonella serovars. WHO Collaborating Centre for Reference and Research on Salmonella, Paris, p. 15.

28. Quinn, P.J., M.E. Carter, B. Markey, and G.R. Carter. 1994. Enterobacteriaceae, In P.J. Quinn, M.E. Carter, B. Markey, and G.R. Carter (ed.). Clinical veterinary microbiology. Wolfe Publishing, London, pp. 209-236.

29. Steinbach, G., and M. Hartung. 1999. Attempt to estimate the share of human Salmonella infections which are attributable to Salmonella originating from swine. Berl. Muench. Tierarztl. Wochenschr. 112:296-300.

30. Tauxe, R.V. 1996. An update on Salmonella. Health Environ. Digest. 10:1-4.

31. Threlfall, E.J., L.R. Ward, J.A. Skinner, and B. Rowe. 1997. Increase in multiple antibiotic resistance in nontyphoidal salmonellas from humans in England and Wales: a comparison of data for 1994 and 1996. Microb. Drug. Resist. 3:263-266. 
32. Threlfall, E.J., F.J. Angulo, and G. Wall. 1998. Ciprofloxacinresistant Salmonella typhimurium DT104. Vet. Rec. 142:255.

33. Threlfall, E.J., L.R. Ward, J.A. Frost, and G.A. Willshaw. 2000. The emergence and spread of antibiotic resistance in food-borne bacteria. Int. J. Food Microbiol. 62:1-5.

34. Van der Wolf, P.J., J.H. Bongers, A.R.S. Elbers, F.M.M.C. Franssen, W.A. Hunneman, A.C.A. van Exsel, and M.J.M. Tielen. 1999. Salmonella infections in finishing pigs in The Netherlands: Bacteriological herd prevalence, serogroup and antibiotic resistance of isolates and risk factors for infection. Vet. Microbiol. 67:263-275.

35. Wegener, H.C., F.M. Aarestrup, P. Gerner-Smidt, and F. Bager. Transfer of antibiotic resistant bacteria from animals to man. Acta Vet. Scand. Suppl. 92:51-57.
36. Wiuff, C., M. Madsen, D.L. Baggesen, and F.M. Aarestrup. 2000. Quinolone resistance among Salmonella enterica from cattle, broilers, and swine in Denmark. Microb. Drug Resist. 6:11-17.

Address reprint requests to: Dr. Luiz, Fernando O.S. Carvalho Departamento de Clínica e Cirurgia Veterinária da Faculdade de Ciências Agrárias e Veterinárias-Unesp Campus de Jaboticabal Via de acesso Prof. Paulo Donato Castellane $s / n$ Jaboticabal, SP, Brazil $14884-900$

E-mail: LFOSC@ @cav.unesp.br 